\title{
Electrocardiographic Criteria of Left Ventricular Hypertrophy in the Presence of Left Bundle Branch Block
}

\author{
Baki KomsuoğLu, M.D., Sükran Ulusoy, M.D., \\ and Ekrem L. Duman, M.D.
}

\begin{abstract}
SUMMARY
When left bundle branch block (LBBB) is present on the electrocardiogram, the diagnosis of left ventricular hypertrophy (LVH) may be difficult. The left ventricular mass in 70 patients with LBBB was estimated by echocardiography, and was compared to the QRS configuration on the electrocardiogram. We found that there was agreement between a monophasic $\mathrm{R}$ pattern in lead $\mathrm{l}$ or $\mathrm{V}_{6}$ (sensitivity $79.3 \%, 70.7 \%$ ) and left ventricular hypertrophy. We suggest that a monophasic $\mathrm{R}$ pattern in $L_{1}$ and $V_{6}$ may provide a useful simple index of left ventricular hypertrophy in the presence of left bundle branch block.
\end{abstract}

\section{Additional Indexing Words:}

Left ventricular hypertrophy Left bundle branch block M-mode echocardiography

7 HE presence of left bundle branch block (LBBB) makes the electrocar1 diographic diagnosis of left ventricular hypertrophy (LVH) difficult. While some authors believe that the electrocardiographic voltage criteria for left ventricular hypertrophy apply in the presence of LBBB, others suggest that the diagnosis of LVH may be unreliable. ${ }^{1)-5}$ Echocardiography is an accuratc method of asscssing left ventricular mass (LVM) ${ }^{6,77}$

We have studied the echocardiographic features of 70 patients with LBBB on their ECG, and compared the results with their QRS configurations.

\section{Patients and Methods}

Patient selection:

Of 3,415 patients who had EGGs recorded at our clinic between October 1983 and October 1987, 83 were identified as having complete LBBB. Only 70 patients could be recalled for echocardiography and a repeat electrocardiogram. Eleven of the 70 patients were clinically normal, 35 had suspected

From the Department of Cardiology, Karadeniz Technical University, Trabzon, Turkey. Received for publication November 26, 1987.

Accepted May 9, 1988. 
coronary artery disease, 14 had hypertension, 5 had valvular heart disease and 5 had idiopathic cardiomyopathy. The patients ranged in age from 28-83 years (average 61 years) and included 34 men and 36 women. Another group of 30 clinically normal subjects with normal electrocardiograms was examined to establish a normal value for left ventricular mass. We also examined another group of 30 subjects with echocardiographically hypertrophic left ventricles and normal conduction.

All electrocardiograms were recorded with a Cambridge chart using multichannel simultaneous leads. All of the following criteria were required for the diagnosis of complete LBBB. ${ }^{8-10}$ )

1. Documented atrioventricular conduction.

2. Absence of the Wolff-Parkinson-White syndrome.

3. QRS duration of $120 \mathrm{~ms}$ or longer.

4. Slurred $\mathrm{R}$ wave in leads $1, \mathrm{a} \mathrm{V}_{\mathrm{R}}$ and $\mathrm{V}_{\boldsymbol{6}}$ and broad, slurred $\mathrm{S}$ wave in $V_{1}$ and $V_{2}$ (QS or $r S$ ).

5. Absence of $Q$ waves in any left heart lead.

6. ST segment depression and/or $\mathrm{T}$ wave inversion in the left precordial lead.

7. $\mathrm{R}$ wave inversion in the left precordial leads (particularly leads 1 and $V_{6}$ ).

All ECGs were coded by one investigator (BK) who had no knowledge of the echocardiographic results. The $R$ and $S$ waves of all 12 leads were carefully measured and recorded, averaged where necessary to the nearest $0.1 \mathrm{mV}$ or $\mathrm{mm}$. The following information was also recorded from the $\mathrm{ECGs}^{8), 11)}$ : height $(\mathrm{mV})$ of waves in leads $1,2,3, a V_{R}, V_{1}$ and $V_{6}$ as well as $S$ wave depth in any lead and the presence or absence of left atrial abnormality.

Echocardiography:

M-mode left ventricular echocardiograms were obtained with an Echo IV Honeywell instrument using a $2.5-\mathrm{MHz}$ transducer at a paper speed of $50 \mathrm{~mm} / \mathrm{sec}$.

Left ventricular echocardiograms were measured at or just below the level of the mitral leaflets, in areas of the recording that showed the largest left ventricular internal dimension (LVIDd). The left ventricular septal and posterior wall dimensions were measured at the peak of the $R$ wave of a simultaneously recorded electrocardiogram (Fig. 1). Left ventricular internal dimension (LVIDd), posterior wall thickness (PWT) and septal thickness (ST) were identified using the "pen convention measurement" regression corrected "cube formula",") and using this formula, left ventricular hypertrophy was defined as left ventricular mass $\geq 215 \mathrm{~g}$.

The echocardiographic features of the patients were divided into 5 groups 


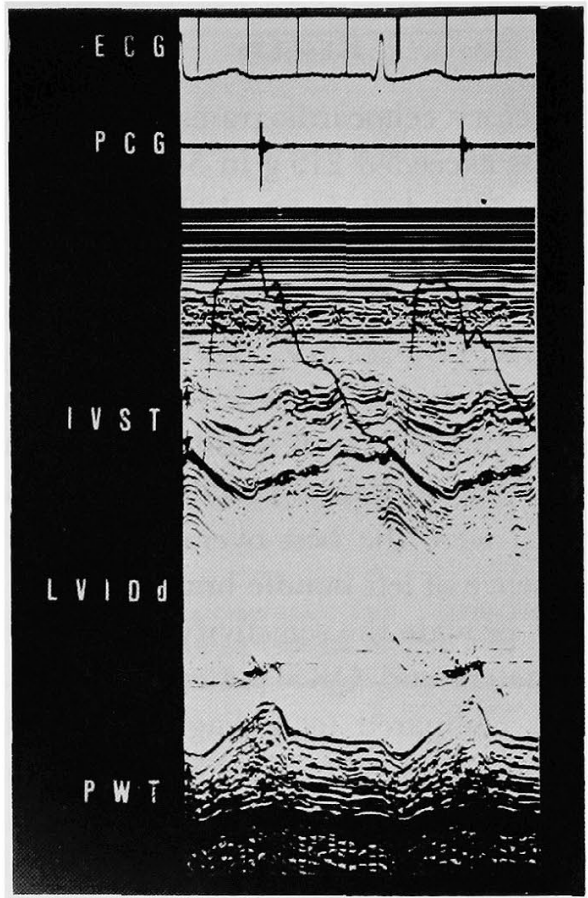

Fig. 1. M-mode echocardiogram. Pen convention measurement.

as follows ${ }^{12)}$ :

1. Normal left ventricular dimension and wall thickness.

2. Concentric left ventricular hypertrophy $(\mathrm{ST}+\mathrm{PWT} \geq 26 \mathrm{~mm}, \mathrm{ST} /$ PWT $\leq 1.3$ and LVIDd $\leq 55 \mathrm{~mm}$ ).

3. Asymmetric septal hypertrophy (ST $\geq 15 \mathrm{~mm}, \quad \mathrm{ST} / \mathrm{PWT} \geq 1.3$, LVIDd $\leq 55 \mathrm{~mm}$ ).

4. Dilated left ventricle (LVIDd $\geq 55 \mathrm{~mm}$ ).

5. Dilated and hypertrophied left ventricle $(\mathrm{ST}+\mathrm{PWT} \geq 26 \mathrm{~mm}, \mathrm{ST} /$ PWT $\leq 1.3$, LVIDd $\geq 55 \mathrm{~mm}$ ).

\section{Statistical methods:}

The sensitivity and specificity of the various electrocardiographic criteria for left ventricular hypertrophy were calculated using standard formulae:

$$
\begin{aligned}
& \text { Sensitivity }(\%)=\frac{\text { True positives correctly diagnosed }}{\text { Total true positives }} \times 100 \\
& \text { Specificity }(\%)=\frac{\text { True negatives correctly diagnosed }}{\text { Total true negatives }} \times 100
\end{aligned}
$$




\section{Results}

Technically satisfactory echocardiograms were obtained in all patients. The left ventricular mass exceeded $215 \mathrm{~g}$ in 58 of 70 patients $(82.8 \%)$, mean left ventricular mass was $342 \pm 49 \mathrm{~g}$ (range $132-710 \mathrm{~g}$ ) (Table I).

The sensitivity and specificity of the various electrocardiographic parameters for the detection of left ventricular hypertrophy are listed in Table II. Several criteria $\left(R_{1}+S_{3} \geq 25 \mathrm{mV}, \quad \mathrm{RaV}_{\mathrm{L}} \geq 11 \mathrm{mV}, \mathrm{R}_{1} \geq 20 \mathrm{mV}, \mathrm{R}_{1}+\right.$ $\mathrm{S}_{3} \geq 17 \mathrm{mV}, \mathrm{RV}_{5^{-6}} \geq 25 \mathrm{mV}$ and left axis $\geq-30$ ) were associated with $100 \%$ specificity but suffered from a lack of sensitivity. Of all EGG criteria examined, the presence of the deepest $S+$ tallest $R \geq 35 \mathrm{mV}$ and left atrial abnormality (enlargement) were the best overall predictors of left ventricular hypertrophy in the presence of left bundle branch block.

Tables III and IV provide the sensitivity and specificity of various electrocardiographic parameters and QRS pattern in the diagnosis of left ventricular hypertrophy as compared to a diagnosis of left ventricular hypertrophy by echocardiography. Good overall single parameters were a monophasic $\mathrm{R}$ in lead 1 (sensitivity $79.3 \%$, specificity $100 \%$ and a monophasic $\mathrm{R}$ in lead $\mathrm{V}_{6}$ (sensitivity $70.7 \%$, specificity $100 \%$ ). The $\mathrm{rSR}$ pattern in $\mathrm{L}_{1}$ was

Table I. Mean Left Ventricular Mass in Normal Subjects, Hypertrophic Subjects with Normal Conduction and Patients with Left Bundle Branch Block

\begin{tabular}{|c|c|c|c|c|c|c|}
\hline \multirow[b]{2}{*}{ Women } & \multicolumn{2}{|c|}{$\begin{array}{l}\text { Normal M-mode } \\
\text { mass }(\mathrm{g})\end{array}$} & \multicolumn{2}{|c|}{$\begin{array}{l}\text { Hypertrophy with } \\
\text { normal conduction } \\
\text { M-mode mass }(\mathrm{g})\end{array}$} & \multicolumn{2}{|c|}{$\begin{array}{l}\text { Left BBB M-mode } \\
\text { mass }(g)\end{array}$} \\
\hline & $(n=17)$ & $126.2 \pm 17$ & $(\mathrm{n}=10)$ & $317.4 \pm 32$ & $(n=36)$ & $309.2 \pm 54$ \\
\hline Men & $(n=13)$ & $147.3 \pm 30$ & $(n=20)$ & $381.6 \pm 17$ & $(\mathrm{n}=34)$ & $336.5 \pm 33$ \\
\hline Total & $(\mathrm{n}=30)$ & $138.4 \pm 21$ & $(\mathrm{n}=30)$ & $354.0 \pm 23$ & $(n=70)$ & $342.1 \pm 49$ \\
\hline
\end{tabular}

Table II. The Percentage Specificity and Sansitivity of Various ECG Measurements of Left Ventricular Hypertrophy in Left BBB

\begin{tabular}{|c|c|c|}
\hline Parameters & Specificity $(\%)$ & Sensitivity $(\%)$ \\
\hline $\mathrm{R}_{1}+\mathrm{S}_{3} \geq 25 \mathrm{mV}$ & 100 & 22.4 \\
\hline $\mathrm{RaV}_{\mathrm{L}} \geq 11 \mathrm{mV}$ & 100 & 13.8 \\
\hline $\mathrm{R}_{1} \geq 20 \mathrm{mV}$ & 100 & 5.2 \\
\hline$\left(\mathrm{R}_{1}+\mathrm{S}_{3}\right)-\left(\mathrm{S}_{1}+\mathbf{P}_{3}\right) \geq 17 \mathrm{mV}$ & 100 & 13.8 \\
\hline$S V_{1}+R V_{5-6} \geq 35 \mathrm{mV}$ & 83.3 & 65.5 \\
\hline Deepest $S+$ Tallest $+R \geq 35 \mathrm{mV}$ & 58.3 & 70.7 \\
\hline$R V_{5 \cdots 6} \geq 25 \mathrm{mV}$ & 100 & 12.1 \\
\hline Left axis $\geq-30$ & 75 & 70.7 \\
\hline Left atrial abnormality & 75 & 41.5 \\
\hline
\end{tabular}


Table III. Electrocardiographic QRS Pattern in Patients with Left BBB

\begin{tabular}{c|c|c}
\hline QRS pattern & Specificity (\%) & Sensitivity (\%) \\
\hline Monophasic R in $\mathrm{L}_{1}$ & 100 & 79.3 \\
$\mathrm{~V}_{6}$ & 100 & 70.7 \\
rR pattern in $\mathrm{L}_{1}$ & 66.7 & 8.6 \\
$\mathrm{~V}_{0}$ & 75 & 6.9 \\
Rr pattern in $\mathrm{L}_{1}$ & 75 & 13.8 \\
$\mathrm{~V}_{\mathrm{n}}$ & 58.3 & 8.6 \\
RR pattern in $\mathrm{L}_{1}$ & 66.7 & 8.6 \\
$\mathrm{~V}_{6}$ & 16.7 & 3.4 \\
rSR pattern in $\mathrm{L}_{1}$ & 91.7 & 1.7 \\
$\mathrm{~V}_{6}$ & 16.7 & 1.7 \\
Other patterns & - & -
\end{tabular}

Table IV. Relation of Echocardiographic Left Ventricular Abnormalities and ECG Pattern Criteria of Left BBB

\begin{tabular}{|c|c|c|c|c|c|}
\hline \multirow{2}{*}{ QRS pattern } & \multicolumn{5}{|c|}{ Echocardiographic status $(\%)$} \\
\hline & $\begin{array}{c}\text { Type } 1 \\
\mathrm{n}=12\end{array}$ & $\begin{array}{c}\text { Type }{ }^{2} \\
\mathrm{n}=16\end{array}$ & $\begin{array}{c}\text { Type } 3 \\
\mathbf{n}=5\end{array}$ & $\begin{array}{c}\text { Type } 4 \\
n=16\end{array}$ & $\begin{array}{c}\text { Type } 5 \\
n=21\end{array}$ \\
\hline \multirow{2}{*}{ Monophasic $\mathrm{R}$ in $\begin{array}{r}\mathrm{L}_{1} \\
\mathrm{~V}_{6}\end{array}$} & - & 75 & 60 & 87.5 & 76.2 \\
\hline & - & 62.5 & 60 & 93.7 & 61.9 \\
\hline \multirow{2}{*}{ 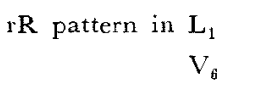 } & 33.3 & 12.5 & 20 & - & 9.5 \\
\hline & 25.0 & 6.2 & 20 & 6.2 & 4.8 \\
\hline \multirow{2}{*}{ Rr pattern in $\begin{array}{l}\mathrm{L}_{1} \\
\mathrm{~V}_{6}\end{array}$} & 25.0 & 25 & 20 & 6.2 & 9.5 \\
\hline & 41.6 & 12.5 & - & 6.2 & 9.5 \\
\hline \multirow{2}{*}{ 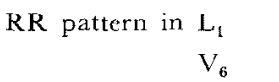 } & 33.3 & - & - & - & 19 \\
\hline & 16.7 & 6.2 & 20 & - & - \\
\hline \multirow{2}{*}{ 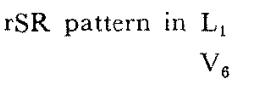 } & 8.4 & - & - & - & 4.8 \\
\hline & 16.7 & - & -- & - & 4.8 \\
\hline
\end{tabular}

very specific $(91.7 \%$ ), but low in sensitivity (1.7\%) (Fig. 2).

Using the echocardiographic left ventricular dimension and thickness, various combinations of criteria were selected from Table IV. A monophasic $\mathrm{R}$ in lead 1 was present in $87.5 \%$ in type 4 and a monophasic $\mathrm{R}$ in $\mathrm{V}_{6}$ was present in $93.7 \%$ in type 4 .

\section{Discussion}

Our results demonstrate a high prevalence (83\%) of left ventricular hypertrophy in a general hospital population with left bundle branch block. This strong association of left ventricular hypertrophy with left bundle branch block has been noted by others. ${ }^{3), 41,13 \text { ) }}$ 
Petersen et $\mathrm{al}^{2)}$ found that $80 \%$ of patients with LBBB had left ventricular hypertrophy as determined from measured left ventricular wall thickness, but only 14 had electrocardiographic evidence of this, while 2 of the 10 patients without left ventricular hypertrophy had positive electrocardiographic criteria. Twenty six of 40 patients with anatomic left ventricular hypertrophy did not have electrocardiographic evidence of this.

Lopez et a ${ }^{14)}$ studied 30 patients with LBBB by means of M-mode echocardiography and calculated the left ventricular mass. In 23 patients with an abnormal left ventricle, the left ventricular mass averaged $241 \pm 12 \mathrm{~g}$. The Sokolow-Lyon score diagnosed 19 of $23(82 \%)$ with 2 false positive results. Recently, Noble et al used echocardiography to determine the prevalence of anatomic left ventricular hypertrophy in 28 patients with LBBB. ${ }^{13)}$ They found anatomic left ventricular hypertrophy in $89 \%$ of their patients and left atrial abnormality was detected in $58 \%$ with 100 specificity. Our sensitivities and specificities of the individual variables in the detection of left
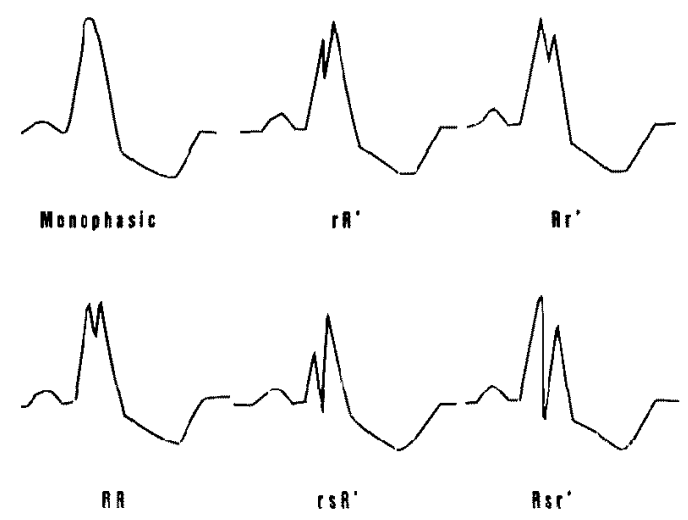

Fig. 2. Example of electrocardiographic QRS pattern.

Table V. Comparison of Selected ECG Criteria for Left Ventricular Hypertrophy

\begin{tabular}{|c|c|c|c|c|}
\hline & $\begin{array}{l}\text { Present study } \\
\text { Left } B B B, L V \\
\text { mass } \geq 215 \mathrm{~g} \\
\text { Sens/Spec }\end{array}$ & $\begin{array}{l}\text { Present study } \\
\text { Normal con- } \\
\text { duction, LV } \\
\text { mass } \geq 215 \mathrm{~g} \\
\text { Sens/Spec }\end{array}$ & $\begin{array}{c}\text { Kafka }^{15} \text { study } \\
\text { Left BBB, LV } \\
\text { mass } \geq 215 \mathrm{~g} \\
\text { Sens/Spec }\end{array}$ & $\begin{array}{c}\text { Reichek }^{7} \\
\text { Normal con- } \\
\text { duction, LV } \\
\text { mass } \geq 215 \mathrm{~g} \\
\text { Sens/Spec }\end{array}$ \\
\hline $\mathrm{RaV}_{\mathrm{L}} \geq 1$ & $22.4 / 100$ & $20 / 100$ & $21 / 89$ & $47 / 99$ \\
\hline$S V_{1}+R V_{5-6} \geq 35$ & $65.5 / 83.3$ & $77 / 70$ & $55 / 73$ & $53 / 86$ \\
\hline Left atrial abnormality & $41.5 / 75$ & $48 / 80$ & $41 / 98$ & $47 / 91$ \\
\hline Left axis $\geq 30$ & $70.7 / 75$ & $14 / 100$ & $30 / 75$ & $33 / 97$ \\
\hline \multirow{2}{*}{ Monophasic $R$ in $\begin{array}{r}L_{1} \\
V_{6}\end{array}$} & $79.3 / 100$ & - & - & - \\
\hline & $70.7 / 100$ & - & - & - \\
\hline
\end{tabular}


ventricular hypertrophy are similar to those reported by others ${ }^{3,44,13), 153}$ (Table V). This confirms that EGG criteria are as valid in the presence of left LBBB as they are in patients with normal conduction.

Most previous studies have used only individual electrocardiographic variables and never used QRS configuration. We found a good agreement between a monophasic $R$ pattern in lead 1 and $V_{6}$. A monophasic $R$ pattern in lead 1 was present in $85.7 \%$ of patients with dilated ventricles. Also, $93.7 \%$ of patients with type 4 (dilated left ventricle) had a monophasic $R$ pattern in $V_{6}$. The best overall single parameter was a monophasic $R$ in lead 1 (specificity $100 \%$, sensitivity $70.7 \%$ ). We suggest that these criteria may provide a useful index of left ventricular hypertrophy in the presence of left bundle branch block.

\section{REFERENGES}

1. Scot RC, Norris RJ: Electrocardiographic-pathologic correlation study of left ventricular hypertrophy in the presence of left bundle branch block (abstr). Circulation 20: 766, 1959

2. Petersen GV, Tikof G: Left bundle branch block and left ventricular hypertrophy: electrocardiographic and pathologic correlation. Chest 59: 174, 1971

3. Zmyslinski RW, Richeson JF, Akiyama T: Left ventricular hypertrophy in the presence of complete left bundle branch block. Br Heart J 43: 170, 1980

4. Cokkinos DV, Demopoulos JN, Helmonas ET, Mallios C, Pagaoglou N, Vorides EM: Electrocardiographic criteria of left ventricular hypertrophy in left bundle branch block. $\mathrm{Br}$ Heart J 40: 320,1978

5. Chapman MG, Pearce ML: Electrocardiographic diagnosis of myocardial infarction in the presence of left bundle branch block. Circulation 16:558, 1957

6. Devereux RB, Reichek N: Echocardiographic determination of left ventricular mass in man. Circulation 55: 613, 1977

7. Reichek N, Devereux RB: Left ventricular hypertrophy: Relationship of anatomic, echocardiographic and electrocardiographic findings. Circulation 63: 1391, 1981

8. Sodi-Pollares D, Calder RM: New Bases of Electrocardiography, CV Mosby, St Louis, 1976

9. Romhilt DW, Bove KE, Norris RJ, Conyers E, Conradi S, Rowlands DT, Scott RC: A critical appraisal for the electrocardiographic criteria for the diagnosis of left ventricular hypertrophy. Circulation 40: 185, 1969

10. Sokolow M, Lyon TP: The ventricular complex in the left ventricular hypertrophy as obtained by unipolar precordial and limb leads. Am Heart J 37: 161, 1949

11. Gubner R, Ungerleider HE: Electrocardiographic criteria of left ventricular hypertrophy. Arch Intern Med 72: 196, 1943

12. Toshima H, Koga Y, Yoshiok H: Echocardiographic classification of hypertensive heart disease. Jpn Heart J 16: 337, 1975

13. Noble LM, Hurpres SB, Monaghan GB: Left ventricular hypertrophy in left bundle branch block. J Electrocardiol 17: 157, 1984

14. Lopez MG, Pereirinha A, de Padua F: The diagnosis of left ventricular hypertrophy in the presence of bundle branch block. in Modern Electrocardiography, ed by Anatalozcy Z, Excerpta Medica, Amsterdam, p 423-27, 1978

15. Kafka H, Burggral GW, Milliken JA: Electrocardiographic diagnosis in the presence of left bundle branch block: an echocardiographic study. Am J Cardiol 55: 103, 1985 